\title{
On the variability in static and cyclic mechanical properties of extruded 7075-T6 aluminum alloy
}

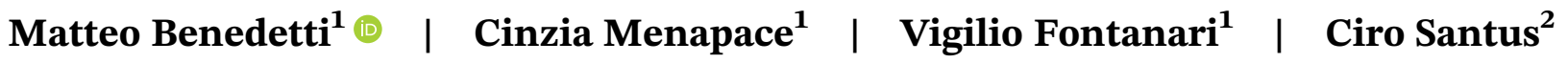

${ }^{1}$ Department of Industrial Engineering, DII, University of Trento, Trento, Italy

${ }^{2}$ Department of Civil and Industrial Engineering, DICI, University of Pisa, Pisa, Italy

\section{Correspondence}

Matteo Benedetti, Department of

Industrial Engineering, DII, University of

Trento. Trento, Italy.

Email: matteo.benedetti@unitn.it

\begin{abstract}
The present paper investigates the variability in the static and cyclic properties of two nominally identical supplies of the aeronautical $\mathrm{Al}$ grade 7075-T6. Samples were extracted from extruded bars of 15 and $60 \mathrm{~mm}$ diameter and with slightly different chemical composition. Noticeable differences were found in tensile strength, total elongation, and low- and high-cycle fatigue strength, despite the nearly identical hardness value. The diverse mechanical behavior has been imputed to different extrusion ratio and therefore work hardening along with a more or less fine distribution of precipitates and dispersoids. The high-cycle fatigue strength was found to be in direct correlation with the monotonic yield strength and the size of the largest intermetallic precipitate. A simple equation based on Murakami sqrt (area) parameter is proposed to predict the fatigue endurance. Tensile tests and microstructural analyses are recommended instead of conventional hardness tests to have a tighter quality control on the mechanical properties of semifinished products.
\end{abstract}

\section{K E Y W O R D S}

aluminum alloys, high-cycle fatigue, intermetallic compounds, low-cycle fatigue, precipitates, tensile strength

\section{1 | INTRODUCTION}

$\mathrm{Al}$ alloys are a very attractive class of metallic materials due to their elevated static strength-to-weight ratio, high thermal and electrical conductivity, good corrosion resistance and machinability, and absence of ductile-to-brittle transition. ${ }^{1}$ For these reasons, they are widely employed in the aeronautic and automotive industry and in cryogenic applications. Since World War II, different heattreatable $\mathrm{Al}$ alloys, namely, 2xxx, 6xxx, 7xxx, and $8 \mathrm{xxx}$ series, have been developed in the civil and military aircraft industry to achieve high static mechanical properties. For instance, $7 \mathrm{xxx}$ series are alloyed with $\mathrm{Zn}$ and $\mathrm{Mg}$ and can be precipitation hardened to the highest strengths of any $\mathrm{Al}$ alloy. ${ }^{2}$ Thus, they are used to fabricate highly stressed aircraft components, such as skins, stringers, panels, and frames of fuselages and wings as well as ribs, spars, and empennages. ${ }^{3}$ The peculiar mechanical properties are conferred by a fine precipitation of intermetallic particles as a consequence of a heat treatment, denoted as T6, consisting of a solubilization, quenching, and final aging. ${ }^{4}$ For instance, in 7075-T6, one of the most widely used 7xxx series alloys and object of the present investigation, the most important hardening precipitate is $\mathrm{MgZn}_{2}$. In addition, traces of additional alloying element are intentionally added to the chemical composition to induce, during the ingot solidification, the formation of fine dispersions of other intermetallic 
particles, typically $\mathrm{Al}_{12} \mathrm{Mg}_{2} \mathrm{Cr}$. They have a beneficial role in controlling the grain size and preventing and/or retarding grain recrystallization during the subsequent heat treatments. ${ }^{5}$ Particular care must be taken to limit the presence of impurities like $\mathrm{Si}$ and $\mathrm{Fe}$, because they can promote the precipitation of particles impacting negatively on the mechanical properties. The Fe-rich precipitates, in fact, are the most detrimental for the nucleation of fatigue cracks since they have an elastic modulus which is almost double respect to the one of the $\mathrm{Al}$ matrix and also a higher hardness respect to other precipitates like $\mathrm{Mg}_{2} \mathrm{Si}$; thus, these particles are not able to accommodate the deformation occurring under loading at the interface with the ductile $\mathrm{Al}$ matrix leading to decohesion and also fracture. ${ }^{6}$ In addition, they generally display a very irregular shape with sharp edges that contribute to cracks initiation under fatigue loading. Concerning the crucial role of $\mathrm{Si}+\mathrm{Fe}$ impurities in decreasing the 7075-T6 mechanical properties, it must be pointed out that a modified version of the 7075 alloy has been developed (named 7475) with a total silicon and iron content limited to $0.22 \%$ wt. (instead of $0.9 \%$ of $7075)^{2}$ for applications that require a combination of higher strength, fracture toughness, and resistance to fatigue crack propagation.

From the above discussion, it is clear that a tight control on the chemical composition is necessary to guarantee adequate and repeatable mechanical properties, especially in the fabrication of components exposed to time varying loads and therefore prone to fatigue damage. This scenario is however further complicated by the fact that $\mathrm{Al}$ semi-finished products can be supplied in several form, for instance extruded bars of different diameter or rolled sheets of different thickness. Consequently, the work hardening experienced by the ingot during these forming processes is different, and this might impact on the grain size and distribution of precipitates and dispersoids. ${ }^{7}$ To this regard, severe plastic deformation is sometimes intentionally introduced to particularly refine the grain size. ${ }^{8}$ For these reasons, it is of paramount importance to precisely know the effect of actual chemical composition and work hardening conditions on the static and fatigue properties when designing critical $\mathrm{Al}$ parts with safety factor approaching the unity, as usually done in the aeronautic context. To address this topic, the present paper investigates the variability in the mechanical properties of two nominally identical supplies of the aeronautical Al grade 7075-T6. Particular care will be paid to understand if such differences in static and fatigue strength can be revealed from conventional quality tests based on non-destructive hardness measures and to devise an alternative procedure to infer the expected high cycle fatigue strength from static tensile tests and microstructural analyses. The paper is organized as follows. Section 2 describes the two investigated material variants and the experimental procedures adopted for their characterization. Section 3 shows the results of microstructural analyses, monotonic, and lowand high-cycle fatigue tests. Concluding remarks are given in Section 4.

\section{2 | MATERIAL AND EXPERIMENTAL PROCEDURES}

The experimentation was carried out on specimens extracted from extruded bars of aeronautical $\mathrm{Al}$ grade 7075-T6 of two different diameters, namely, 15 and $60 \mathrm{~mm}$. The corresponding specimen variants will be denoted as $\phi 15$ and $\phi 60$, respectively. The raw material suppliers declared that both heat treatment (solubilization at $470^{\circ} \mathrm{C}$ for $1 \mathrm{~h}$ followed by water quenching and aging at $120^{\circ} \mathrm{C}$ for $24 \mathrm{~h}$ ) and chemical composition were compliant with the material standard. To confirm this, quantometer analyses were carried out on coupons extracted from the bars. The results are listed in Table 1 and compared with the allowable chemical composition. As expected, the two material variants display very similar chemical compositions, and both of them are conforming with the standard. The only relevant differences concern the $\mathrm{Si}$ and Fe content, slightly higher in the $\$ 60$ variant, as well as Mn though less important in terms of impurities. The role of these impurities will be discussed in the following.

For the metallographic analyses, coupons cut in both longitudinal and transversal direction from the fatigue test bars were mounted in resin, polished, and etched with a solution of nitric acid $(15.5 \mathrm{ml})$, hydrofluoric acid $(0.5 \mathrm{ml})$ and chromium trioxide $(3 \mathrm{~g})$ in $84 \mathrm{ml}$ of distilled

TA B LE 1 Chemical composition of the $\phi 60$ and the $\phi 15$ alloys

\begin{tabular}{lccc} 
Element \% wt. & $\mathbf{\phi 6 0}$ & $\boldsymbol{\phi 1 5}$ & Nominal \\
\hline $\mathrm{Si}$ & 0.206 & 0.071 & $<0.4$ \\
$\mathrm{Fe}$ & 0.245 & 0.126 & $<0.5$ \\
$\mathrm{Cu}$ & 1.58 & 1.49 & $1.2-2$ \\
$\mathrm{Mn}$ & 0.160 & 0.046 & $<0.3$ \\
$\mathrm{Mg}$ & 2.04 & 2.21 & $2.1-2.9$ \\
$\mathrm{Zn}$ & 5.32 & 5.22 & $5.1-6.1$ \\
$\mathrm{Ti}$ & 0.082 & 0.052 & $<0.2$ \\
$\mathrm{Cr}$ & 0.191 & 0.206 & $0.18-0.28$ \\
\hline $\mathrm{Al}$ & 90.0 & 90.4 & $87.1-91.4$ \\
\hline
\end{tabular}

Note: The nominal composition of the 7075 alloy (according to ASM international handbook) is reported in the third column. 
water. The specimens were examined using a light optical microscope Zeiss Axiophot and a scanning electron microscope (SEM) JEOL IT 300 equipped with an energy dispersive X-Ray spectroscopy (EDXS). The image analysis program Image $\mathrm{J}$ was used for the measurement of the intermetallic precipitates dimension. Specifically, 60 precipitates per each variant have been analyzed on polished areas of comparable size. This particle amount has been selected on the base of a sensitivity analysis of mean and standard deviation of the particles' characteristic dimensions to the sample size.
Microhardness was measured on the metallographic sections using a Vickers indenter under a load of $100 \mathrm{~g}$, whereas Vickers macro-hardness HV10 was measured on transversal cross-sections cut from the fatigue test bars applying a load of $10 \mathrm{~kg}$ on a Emco-Test M4U 025 hardness tester.

Monotonic tensile tests (initial strain rate of $10^{-4} \mathrm{~s}^{-1}$ ) were performed according to the standard ASTM E8 on a dog-bone specimen aligned with the longitudinal (L) orientation of the bars, whose geometry is shown in Figure 1A. Three tests were replicated for each variant at
FI G URE 1 Geometry of the specimens used in the experimentation for (A) monotonic tensile, (B) straincontrolled LCF, and (C, D) loadcontrolled HCF tests. (C) and (D) were used for $\phi 60$ and $\phi 15$ specimens respectively
(A)

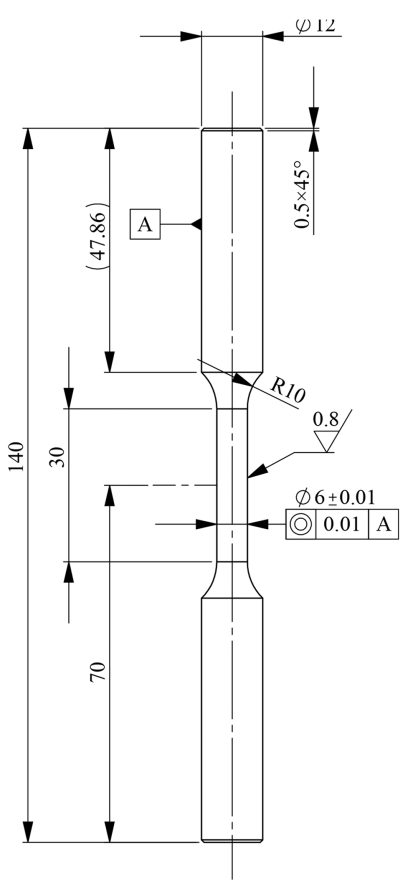

(C)

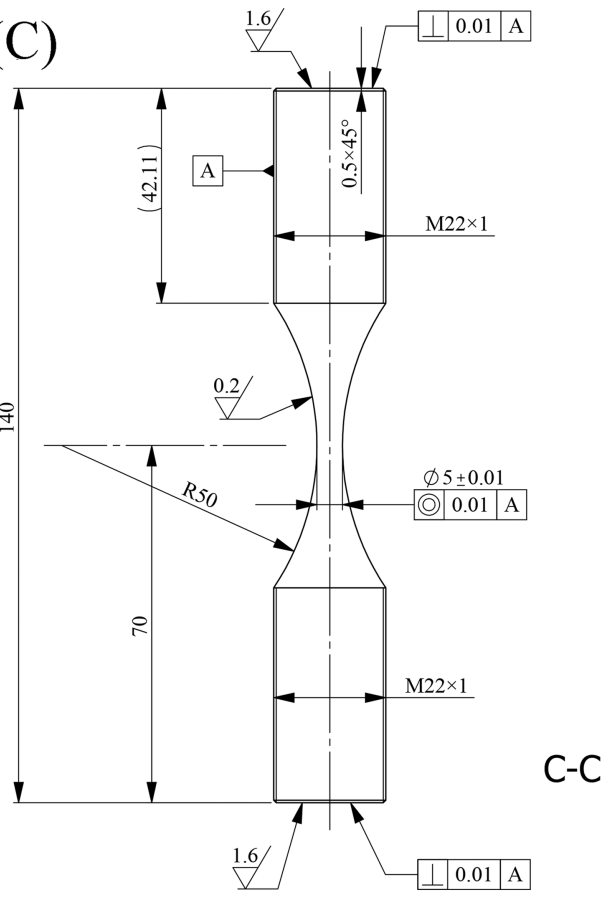

$\mathrm{C}-\mathrm{C}$

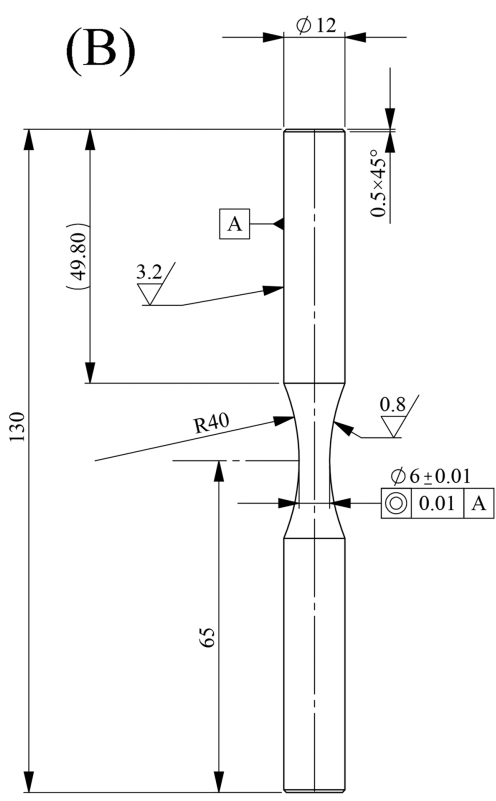

(D)

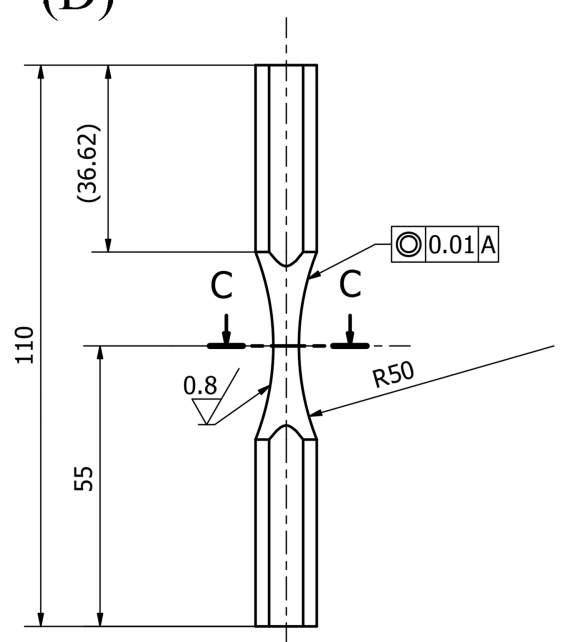

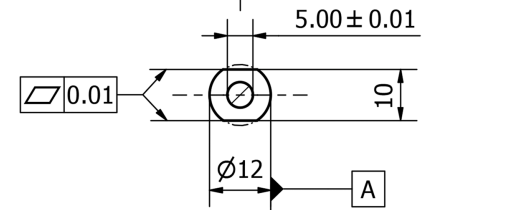


room temperature $\left(25^{\circ} \mathrm{C}, 60 \%\right.$ R.H. $)$ using a servohydraulic universal testing machine INSTRON 8516, equipped with hydraulic grips, a load cell of $100 \mathrm{kN}$ (nonlinearity $\pm 0.1 \%$ of R.O.), and an axial extensometer (10 mm gauge length, nonlinearity $\pm 0.15 \%$ of R.O.). The yield strength was determined as the $0.2 \%$ offset.

To investigate the cyclic and low-cycle fatigue (LCF) behavior, a specific experimentation was conducted on axisymmetric hourglass coupons (illustrated in Figure 1B) with gage diameter of $6 \mathrm{~mm}$ extracted from the same material supply. Specifically, straincontrolled fatigue tests are performed according to the standard ASTM E606 using the above-mentioned servohydraulic universal testing machine INSTRON 8516, in this case equipped with a diametral (transversal) extensometer (nonlinearity $\pm 0.15 \%$ of R.O.). Each sample is subjected to strain cycles with constant amplitude, triangular waveform, and constant strain rate of $1 \times 10^{-2} \mathrm{~s}^{-1}$. Fully reversed strain amplitudes (strain ratio $R_{\varepsilon}=-1$ ) are applied until final failure at four diametral strain amplitudes comprised in the range $[0.0002,0.005]$. The diametral $\left(\varepsilon_{d}\right)$ is converted into axial strain $\left(\varepsilon_{a x}\right)$ according to the following equation prescribed by ASTM E606, assuming plastic incompressibility:

$$
\varepsilon_{a x}=\frac{\sigma_{a x}}{E}(1-2 \nu)-2 \varepsilon_{d},
$$

where $\sigma_{a x}$ is the axial stress, $E$ is the Young's modulus (reported in Table 1), and $v$ the Poisson's ratio, taken equal to 0.33 . The LCF data are elaborated by dividing the total strain amplitude of the half-life stabilized hysteresis loops into its elastic $\left(\varepsilon_{a, e l}\right)$ and plastic $\left(\varepsilon_{a, p l}\right)$ components, which are then separately fitted according to the Basquin and Coffin-Manson equations, respectively:

$$
\begin{aligned}
& \varepsilon_{a, e l}=\frac{\sigma_{f}^{\prime}}{E}\left(2 N_{f}\right)^{b}, \\
& \varepsilon_{a, p l}=\varepsilon_{f}^{\prime}\left(2 N_{f}\right)^{c} .
\end{aligned}
$$

For this purpose, linear regressions in the logarithmic scale are done according to the indications prescribed in the standard ASTM E739.

To evaluate the high-cycle fatigue (HCF) behavior, fatigue tests were conducted in the L-orientation on hourglass axisymmetric specimens depicted in Figure 1C,D according to the standard ASTM E466. Specimen geometry depicted in Figure 1C,D was used for $\phi 60$ and $\phi 15$ variant, respectively. It can be noted that the gage section geometry is identical, characterized by the same minimum diameter $(5 \mathrm{~mm})$ and same fillet radius $(50 \mathrm{~mm})$. The specimen heads are different because of the different diameter of the bar, which the specimens were machined from. Specifically, the geometry shown in Figure 1C displays threaded ends M22, which allowed the specimen to be tested in a resonant testing machine Rumul Microtron $20 \mathrm{kN}$. The great enlargement of the gripping heads with respect to the gage section was necessary to avoid specimen failure far from the gage section as a result of fretting phenomena at the threaded connections. Such enlargement was not possible in specimens extracted from $\phi 15$ bars. For this purpose, the terminal part of such specimen geometry was flattened via milling as shown in Figure 1D. In this way, the specimens can be tested using hydraulic grips mounted on the mentioned servohydraulic testing machine without the onset of undesired fretting damage. The HCF characterization was performed in laboratory environment in load control at load ratio $R=0.1$. $\phi 15$ and $\phi 60$ specimens were tested at 20 and $120 \mathrm{~Hz}$, respectively. Experimental investigations carried out in the frame of the research published in Benedetti et al. ${ }^{9}$ attested very similar fatigue outcomes obtained with the two testing machines operating at different frequencies. Fifteen specimens per each variant were tested at different stress amplitudes. Run-out tests were terminated at $5 \times 10^{6}$ and $3 \times 10^{7}$, in the former and latter case, respectively, when no fracture took place. The S-N curves were found to be well represented by the following model:

$$
\sigma_{a}=k_{1}+\frac{k_{2}}{N_{f}^{m}}
$$

The scatter of the fatigue data was assessed by computing the estimated regression variance assumed to be uniform for the whole fatigue life range and expressed by

$$
S^{2}=\frac{\sum_{i=1}^{q}\left(\sigma_{a, i}-\hat{\sigma}_{a, i}\right)^{2}}{q-p},
$$

where $\sigma_{a, i}$ is the $i$ th fatigue amplitude data point, $\hat{\sigma}_{a, i}$ is its estimator, $q$ is the number of data elements, and $p$ is the number of parameters in the regression $(p=3$ in the present case).

Fatigue fracture surfaces have been investigated using a JEOL JSM-IT300LV scanning electron microscope equipped with an energy-dispersive X-ray spectroscopy (EDXS) probe for quantitative chemical analysis. 


\section{3 | RESULTS AND DISCUSSION}

\section{1 | Microstructural analysis}

The observation results of light optical microscope are shown in Figures 2-7. In Figure 2 the unetched microstructures of $\phi 60$ and $\phi 15$ alloys are compared. The unetched surfaces of the metallographic samples highlight the intermetallic precipitates, which display a significantly higher dimension in the $\phi 60$ variant.

The size of these compounds has been measured through image analysis as shown in Figure 2C,D,

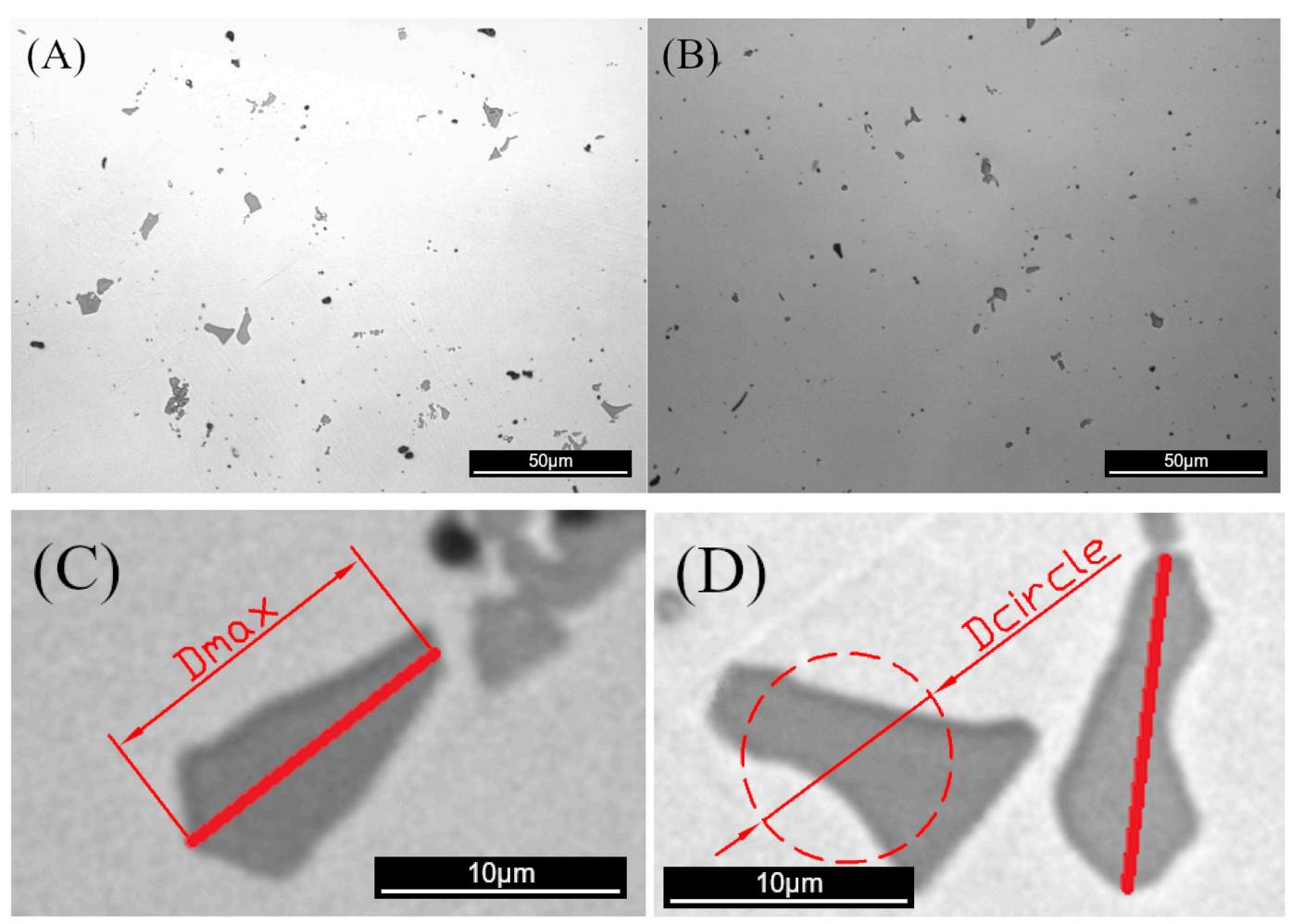

F I G U RE 2 (A and B) Unetched microstructures of $\phi 60$ and $\phi 15$ variants, respectively. (C and D) Image analysis of precipitates dimension. Schematic definition Dmax and Dcircle dimensions used to define the characteristic size of the precipitates [Colour figure can be viewed at wileyonlinelibrary.com]
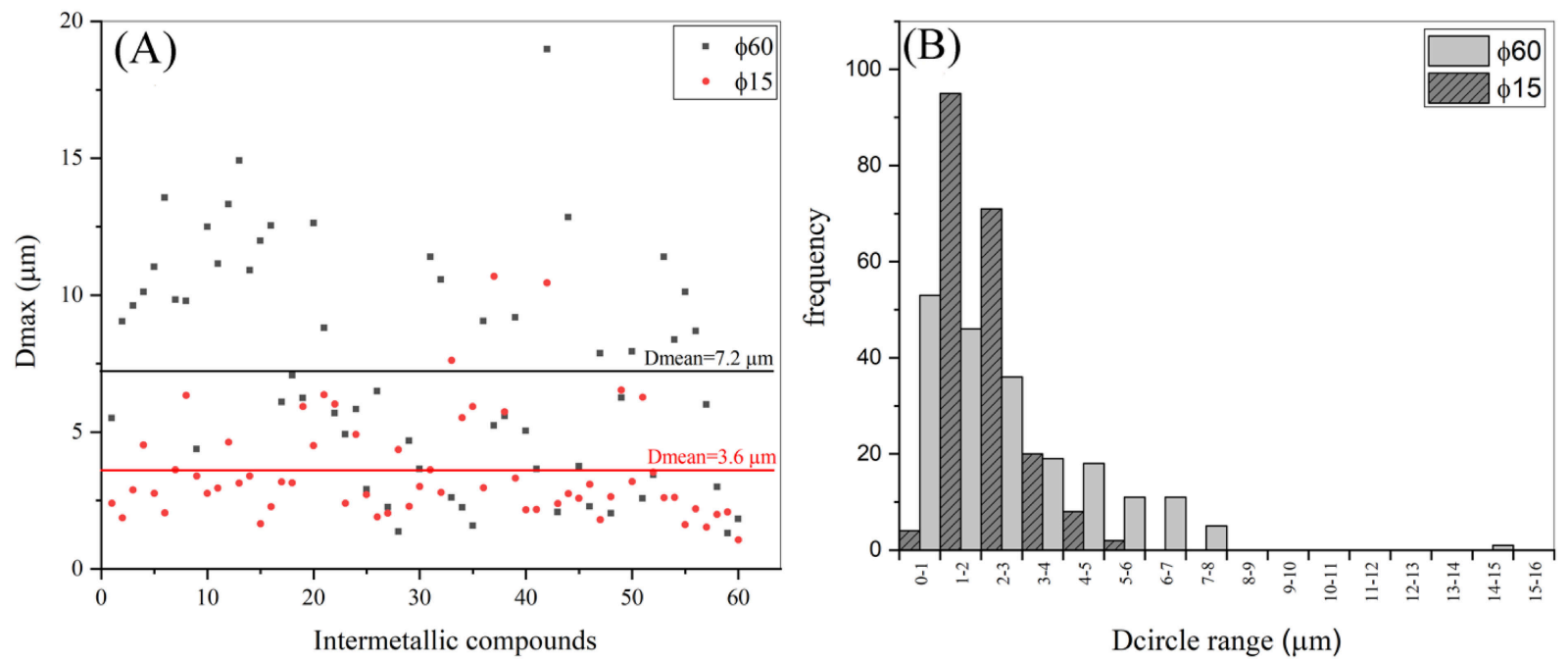

F I G U RE 3 (A) Dmax of the intermetallic compounds of $\phi 60$ and $\phi 15$; (B) Dcircle distribution of $\phi 60$ and $\phi 15$ [Colour figure can be viewed at wileyonlinelibrary.com] 

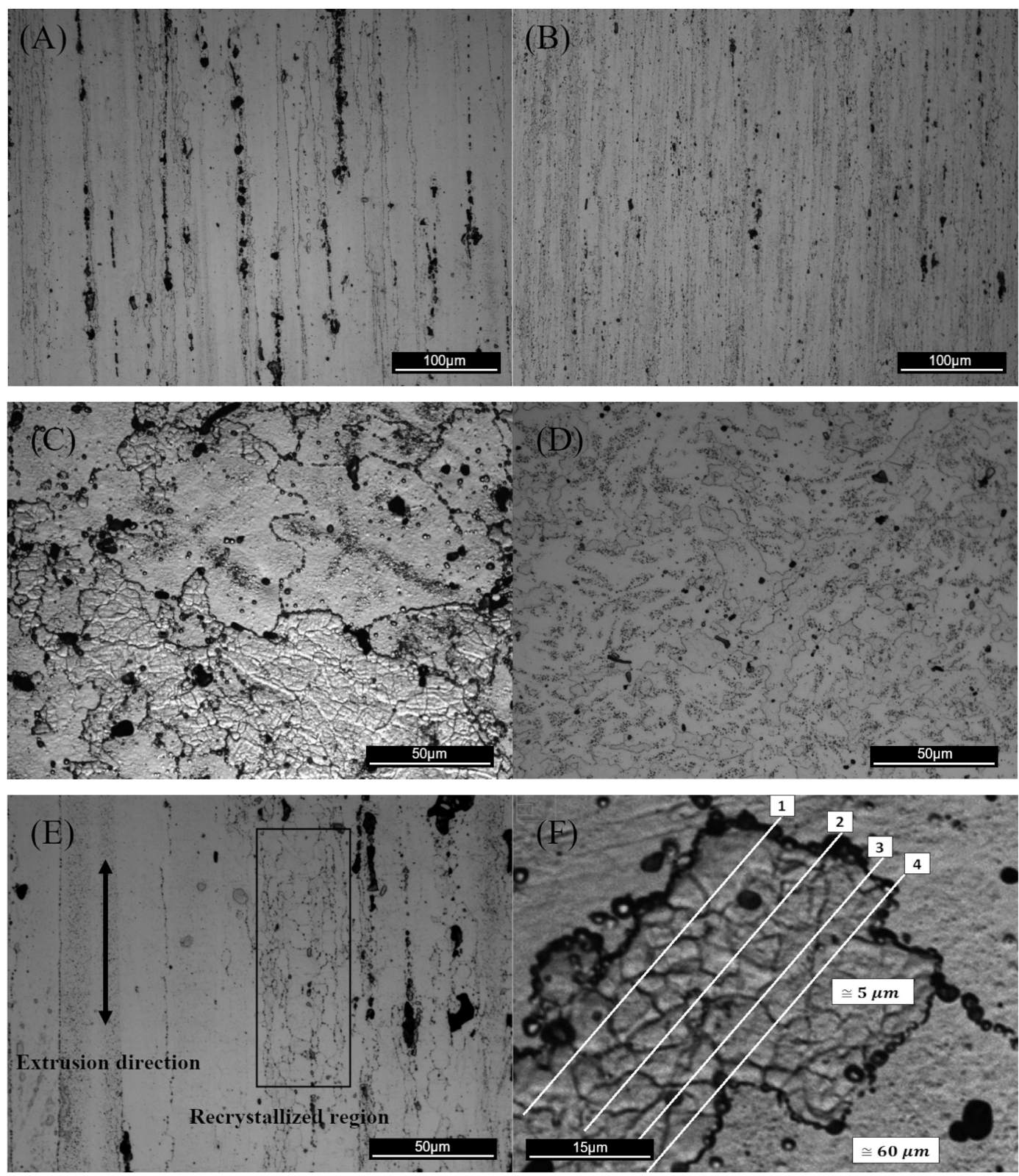

F I G U R E 4 Microstructures of $\phi 60$ (A, C) and $\phi 15$ (B, D) alloys. Longitudinal direction (A, B); transversal direction (C, D).

(E) Longitudinal cross section of $\phi 60$ alloy showing a recrystallized region. (F) Intercept method applied to a recrystallized region of the $\phi 60$ alloy to measure the grain size

calculating a mean value. It is $7.2 \mu \mathrm{m}$ for the $\phi 60$ alloy (with a minimum of 1.3 and a maximum of $19 \mu \mathrm{m}$ ) and $3.6 \mu \mathrm{m}$ for the $\phi 15$ alloy (with a min-max range of 1.1$10.7 \mu \mathrm{m}$ ). The distribution of the precipitates dimension is reported in Figure 3A,B. Figure 3A shows the maximum dimension of the intermetallic compounds (Dmax) measured on the metallographic section of $\phi 60$ and $\phi 15$, while Figure 3B compares the distribution of Dcircle of the two alloys, which is the diameter of the circle having the same area of the particle measured. The maximum value thereof is 15.2 and $5.4 \mu \mathrm{m}$ for $\phi 60$ and $\phi 15$, respectively.
In Figure $4 \mathrm{~A}-\mathrm{D}$, the etched microstructures of $\phi 60$ and $\phi 15$ alloys are compared in both longitudinal and transversal direction. The $\phi 15$ alloy has a much finer grain size, in addition to the much finer intermetallics dimension shown in Figure 2. Both alloys have a bimodal grain size with regions in which a recrystallized grain is visible, which is formed as a result of the plastic deformation induced by the hot extrusion process. ${ }^{10-12}$ One of these recrystallized areas is shown in Figure 4E for the $\phi 60$ sample. The grain size has been measured through the intercept method applied to both the fine and the big grain size areas, as shown in Figure 4F for the $\phi 60$ alloy. 

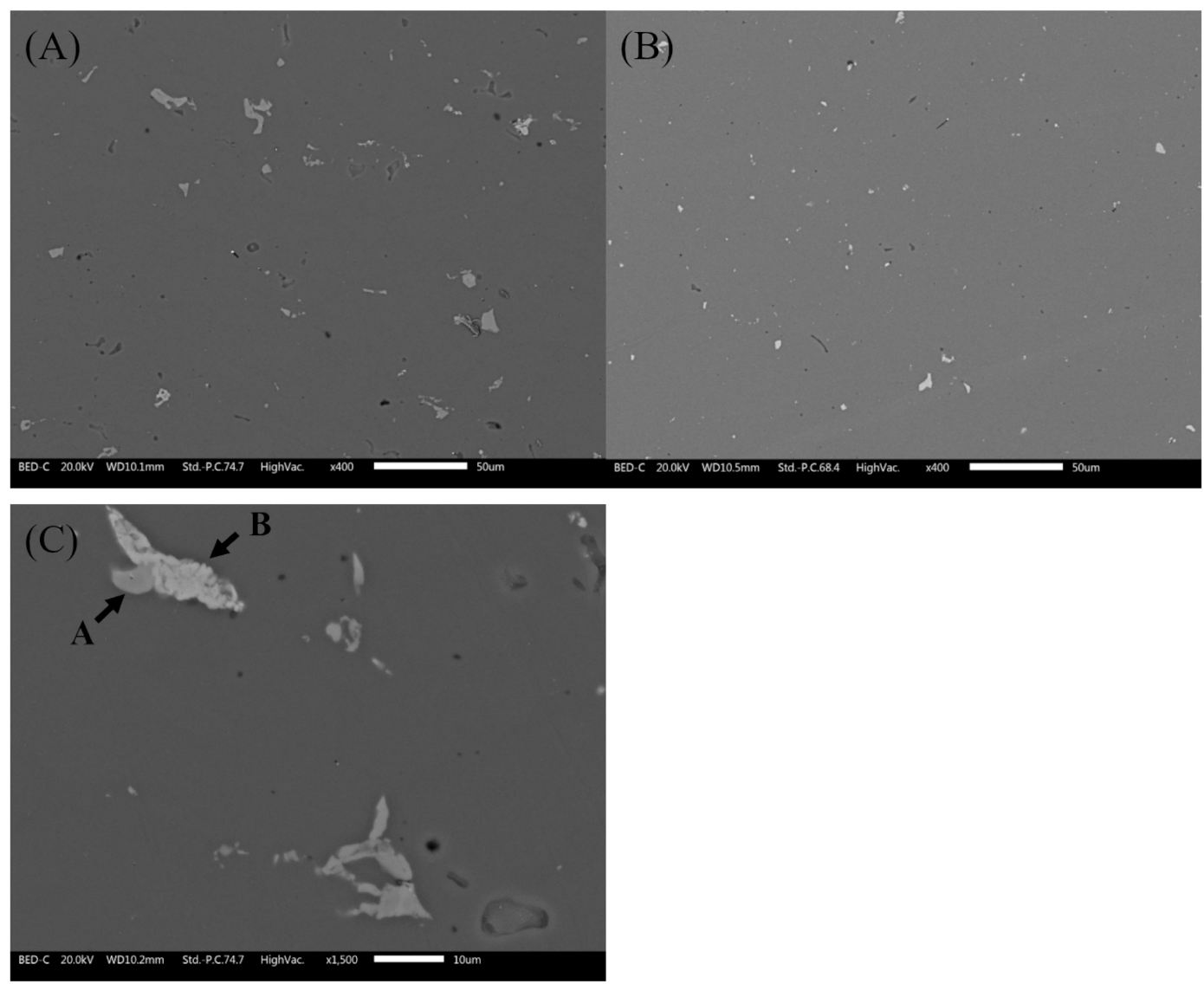

F I G U R E 5 SEM micrograph showing the intermetallic precipitates in the $\phi 60$ (A) and $\phi 15$ (B) alloys. (C) Precipitate analysis carried out on the $\phi 60$ sample

The mean grain sizes found for the $\phi 60$ alloy are 5 and $60 \mu \mathrm{m}$ in the recrystallized and unrecrystallized areas, respectively. These unrecrystallized regions show a fine network of precipitates on the grain boundaries, probably $\mathrm{Al}_{7} \mathrm{Cu}_{2} \mathrm{Fe}$ and $\mathrm{Mg}_{2} \mathrm{Si}$ that typically arrange along the grain boundaries and are stable up to $490^{\circ} \mathrm{C} .^{4,13}$ These particles, potentially detrimental for the mechanical properties, form when there is a high $\mathrm{Si}$ and Fe impurity level, as in the case of the $\phi 60$ alloy. For the $\phi 15$ alloy, on the contrary, no grain boundary precipitation was detected; therefore, the grain boundaries are clearly visible only in the recrystallized regions. The mean grain size measured on these areas is $2.5 \mu \mathrm{m}$, much lower than the $5 \mu \mathrm{m}$ measured for the $\phi 60$ alloy. This difference indicates a higher deformation degree in the $\phi 15$ alloy, related to its higher extrusion ratio. ${ }^{7}$ The higher extrusion ratio is also responsible for the significant refinement of the intermetallic compounds observed on this alloy.

The results of SEM investigations are shown in Figures 5 and 6 . In particular, the intermetallic compounds of $\phi 60$ and $\phi 15$ specimens are visible in the micrographs of Figure 5A,B, respectively. A higher magnification is reported in Figure $5 \mathrm{C}$ for the coarser precipitates found in $\phi 60$.
The results of EDXS analyses carried out on $\phi 60$ and $\phi 15$ alloy are reported in Figure 6 . The particle marked by arrows in Figure 5C is composed by two different intermetallics. The left part of the particle (labeled A) has a dark gray color, and it was identified as $\mathrm{Al}_{23} \mathrm{Fe}_{4} \mathrm{Cu}$ (Figure 6A), while the light gray part of the same particle (B) showed a higher amount of $\mathrm{Cu}$, and it was identified as $\mathrm{Al}_{7} \mathrm{Cu}_{2} \mathrm{Fe}$ (Figure 6B). An example of EDXS analysis referring to the $\phi 15$ sample is reported in Figure $6 \mathrm{C}$, where the particle surrounded by a rectangle has been identified as $\mathrm{Al}_{23} \mathrm{Fe}_{4} \mathrm{Cu}$. The same intermetallic compounds, $\mathrm{Al}_{23} \mathrm{Fe}_{4} \mathrm{Cu}$ and $\mathrm{Al}_{7} \mathrm{Cu}_{2} \mathrm{Fe}$, were detected on both alloys with the only difference in their size. These types of intermetallics are in agreement with literature data about 7075 alloy $^{14,15}$ and, as pointed out, are the most detrimental for the mechanical properties of this alloy.

Other kinds of intermetallics reported in the literature are $\mathrm{Mg}_{2} \mathrm{Si}$ and $\mathrm{MgZn}_{2}{ }^{4} \cdot \mathrm{Mg}_{2} \mathrm{Si}$ particles form during the solidification and increase significantly in size if they are solubilized and aged for long times at high temperature. ${ }^{4}$ They appear under the SEM as dark, almost rounded precipitates, corresponding presumably to the particles indicated by arrows in Figure $6 \mathrm{C}$. These precipitates are too small to be analyzed by EDXS. In the present research, in 

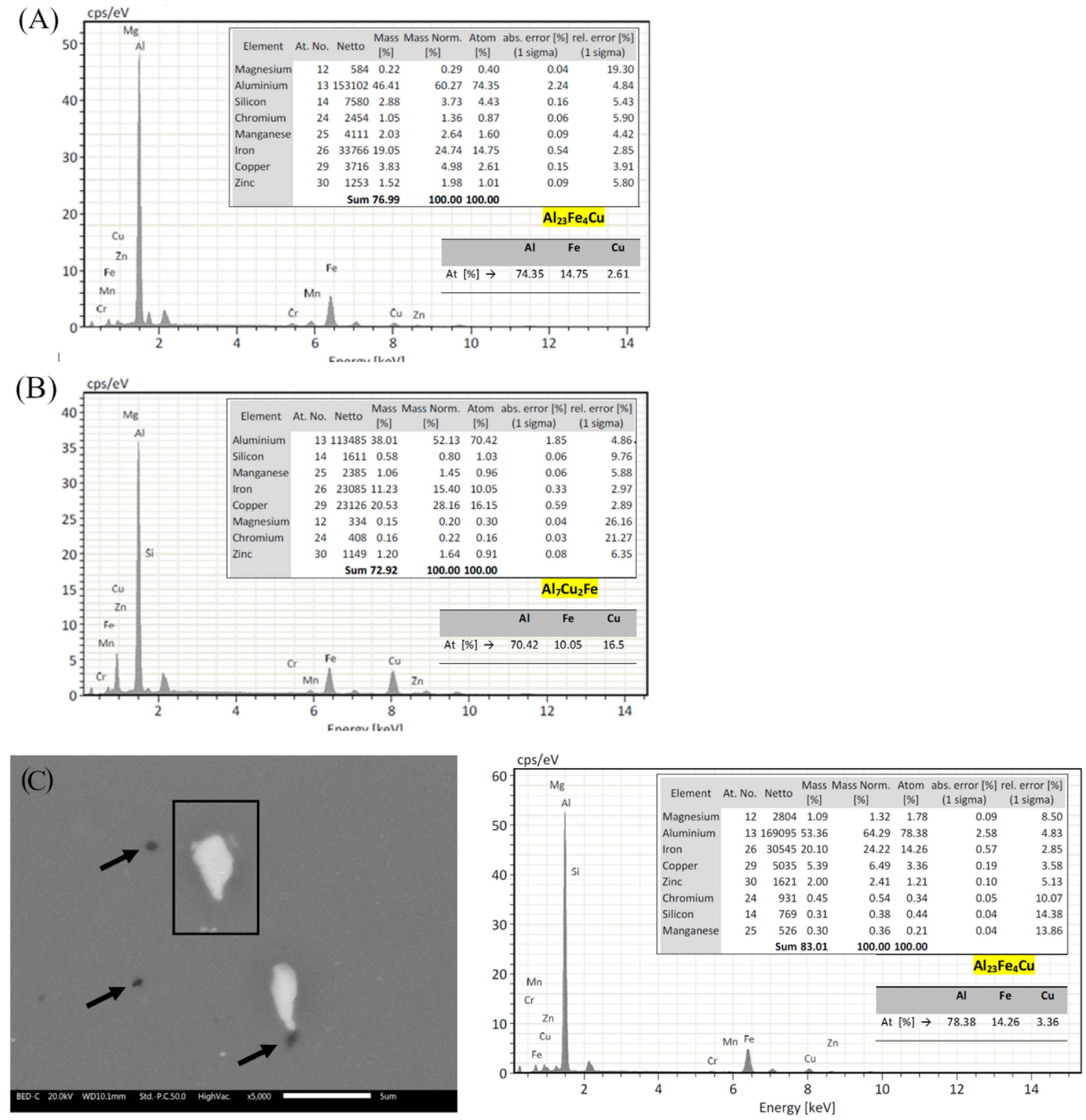

F I G U RE 6 Results of EDXS analyses. (A and B) Composition of particles A and B found in $\phi 60$ condition and shown in Figure 5C, respectively. (C) Analysis of the precipitates found in $\phi 15$ variant [Colour figure can be viewed at wileyonlinelibrary.com]

fact, the combination of temperature and time applied for the T6 treatment allowed to limit the size of these intermetallics, which is positive for the mechanical properties. $\mathrm{MgZn}_{2}$ particles were not detected because of their complete dissolution during the solubilization and agehardening treatment at the temperature applied in the present research. ${ }^{4,16}$

Hardness and microhardness measured on the two alloys are reported in Table 2. Importantly, the $\phi 15$ variant exhibits slightly higher values, apparently due to the finer grain size and the finer and more homogeneous distribution of the intermetallic compounds.

\section{2 | Monotonic properties}

Representative true stress-true strain curves are plotted in Figure 7 for the two material variants; mean values of materials parameters obtained from the analysis of tensile data are summarized in Table 3 and compared with typical properties reported in ASM Handbook ${ }^{1}$ as averages for various sizes, product forms, and methods of manufacture as well as minimum values prescribed by standard DIN EN 755-2. Importantly, both variants display tensile properties in excess of the above-mentioned typical properties, apart from a slightly lower total 
elongation shown by $\phi 60$ (10\% vs. 11\%), and by far higher than the minimum allowable values. Interestingly, despite the modest difference in hardness and microhardness (Table 2), the two material variants display very different monotonic properties. The variant $\phi 15$, thanks to its finer grain size and precipitates dispersion, displays superior yield stress ( $10 \%$ higher), ultimate tensile strength ( $8 \%$ higher), and total elongation (29\% higher), thus boasting a better combination of strength and ductility. On the contrary, the similar values of uniform elongation, namely, the portion of the tensile curve spent to uniformly elongate the sample before the localization of plastic strain at the necking, suggest that the two conditions have comparable formability.

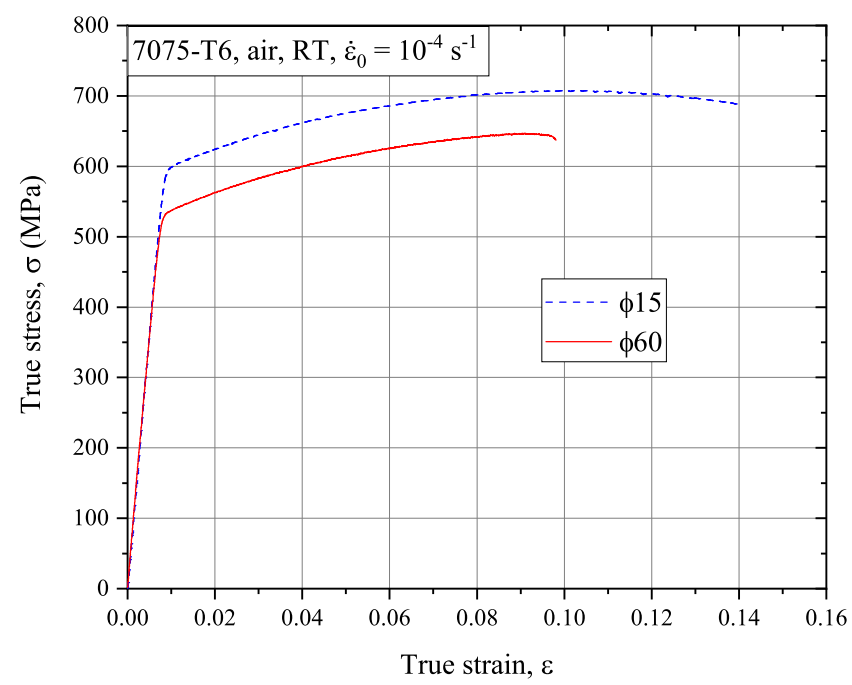

F I G URE 7 Monotonic tensile curve of the investigated Al variants [Colour figure can be viewed at wileyonlinelibrary.com]

TA B L E 2 Hardness and microhardness of the two alloys

\begin{tabular}{|c|c|c|c|}
\hline \multicolumn{2}{|c|}{ Hardness HV10 } & \multicolumn{2}{|c|}{ Microhardness $H V_{0.1}$} \\
\hline$\phi 60$ & $\phi 15$ & $\phi 60$ & $\phi 15$ \\
\hline $175.4 \pm 1.5$ & $182.4 \pm 1.8$ & $169.8 \pm 3$ & $177.8 \pm 1.9$ \\
\hline
\end{tabular}

\section{3 | Cyclic and low-cycle fatigue properties}

The evolution of the cyclic stress amplitude is shown in Figure $8 \mathrm{~A}, \mathrm{~B}$, for $\phi 15$ and $\phi 60$, respectively, as a function of the number of cycles for all the tested strain amplitudes. It can be noted that $\phi 15$ exhibits a fairly stable cyclic behavior, while $\phi 60$, especially at the highest strain amplitudes, displays a remarkable cyclic hardening. As a result, higher stress amplitudes are reached in $\$ 60$ when imparting the same strain range. In addition, it was not possible to impart to $\phi 15$ the highest value of strain amplitude explored in $\phi 60$ (0.016), as fracture occurred just after the first reversal. Stabilized half-life stressstrain hysteresis loops are shown in Figure 8C,D, for $\phi 15$ and $\phi 60$, respectively. It can be noted that the hysteresis cycles are approximately symmetric with respect to the horizontal (strain) axis at all the explored strain amplitudes. This is in contrast with what found in Benedetti et al. ${ }^{17}$ for $7075-\mathrm{T} 651$, which, unlike the present T6 variants, received a stretching treatment prior to aging resulting in an asymmetric tension-compression behavior.

The results of the LCF tests are plotted in Figure 8E. The best-fit coefficients of the Basquin and CoffinManson equations (Equations 2a and 2b) used to interpolate the experimental data are listed in Table 4.

Looking at Figure $8 \mathrm{E}$ and Table 4, it can be observed that the contribution of elastic strain to the LCF behavior is very similar in the two material conditions; conversely, the $\phi 60$ variants, presumably due to lower hardening received during extrusion, exhibits much higher plastic resources than $\phi 15$. In this latter case, the contribution of plastic strain to LCF behavior is evident only until about 200 reversals to failure. Cyclic hardening differences between the two variants have been detected also in terms of cyclic stress-strain curve. This was determined from the half-life hysteresis loops of the LCF tests. Both cyclic and monotonic stress-strain curves were fitted using the RambergOsgood equation:

T A B L E 3 Monotonic tensile properties based on three replicated tests per material variant with respect to the rolling direction

\begin{tabular}{|c|c|c|c|c|c|c|c|}
\hline Variant & E (GPa) & $\mathrm{S}_{\mathbf{Y}}(\mathrm{MPa})$ & $\mathrm{S}_{\mathrm{U}}(\mathrm{MPa})$ & $\sigma_{\mathrm{f}}(\mathrm{MPa})$ & T.E. (\%) & U.E. (\%) & R.A. (\%) \\
\hline$\phi 60$ & $70.5 \pm 0.2$ & $531 \pm 7.3$ & $595 \pm 5.9$ & $663 \pm 2.5$ & $10 \pm 0.7$ & $7.5 \pm 0.6$ & $13 \pm 4.6$ \\
\hline$\phi 15$ & $70.3 \pm 0.3$ & $592 \pm 4.2$ & $648 \pm 3.3$ & $722 \pm 2.2$ & $14 \pm 1.1$ & $8.1 \pm 0.7$ & $18 \pm 6.7$ \\
\hline DIN EN 755-2 & 72 & 480 & 540 & - & 7 & - & - \\
\hline
\end{tabular}

Note: Standard error corresponds to $1 \sigma$ uncertainty band.

Abbreviations: E, Young's modulus; $\sigma_{\mathrm{f}}$, true fracture stress; R.A., reduction in area; $\mathrm{S}_{\mathrm{U}}$, ultimate tensile strength; $\mathrm{S}_{\mathrm{Y}}, 0.2 \%$ yield stress; T.E., total elongation; U.E., uniform elongation. 


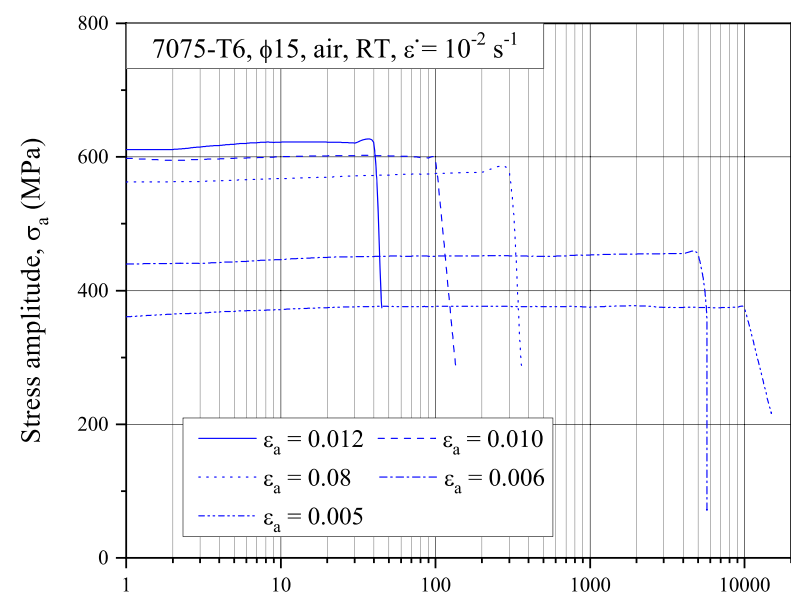

(A)

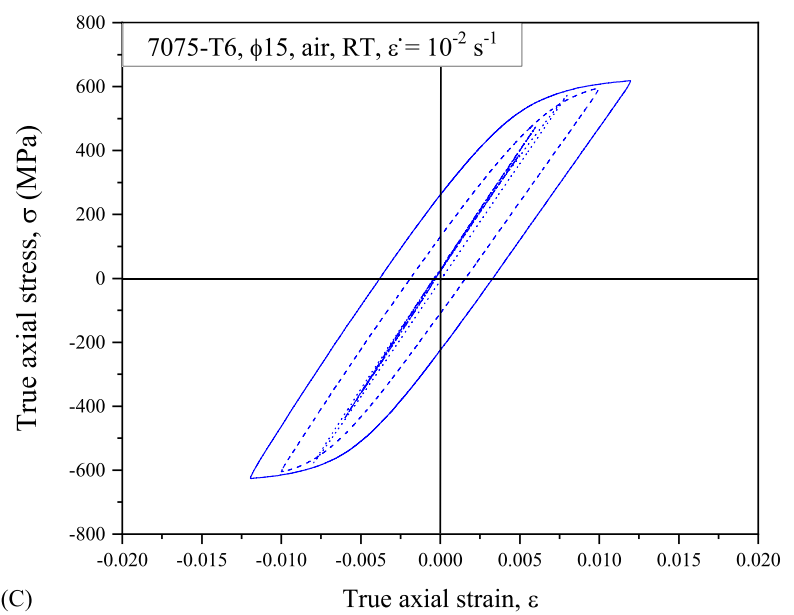

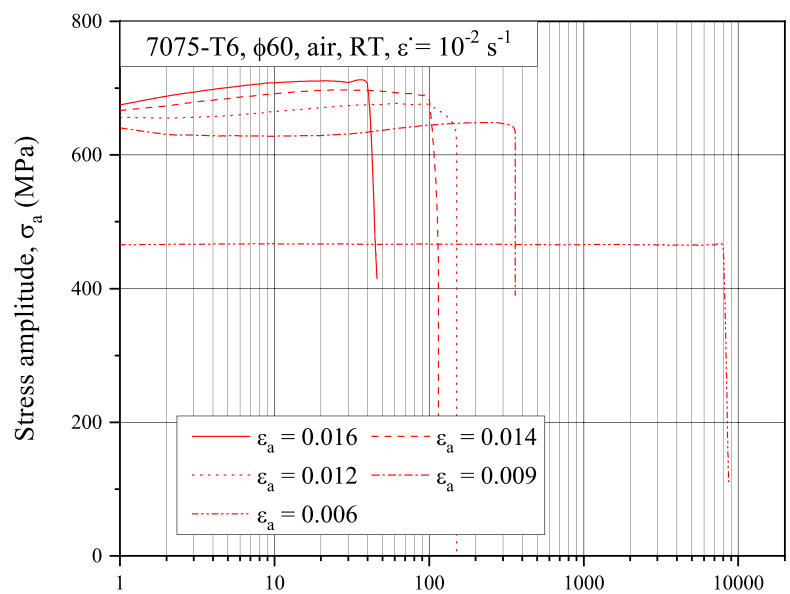

(B)

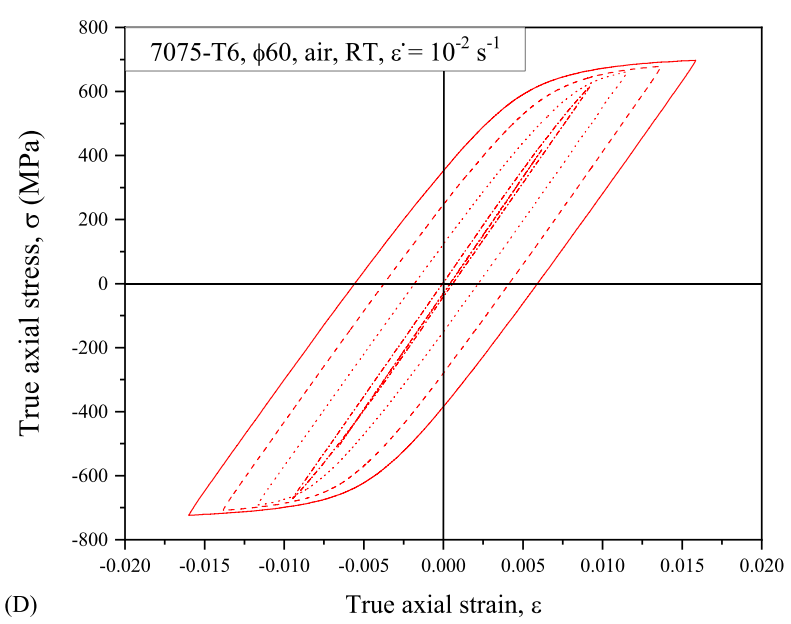

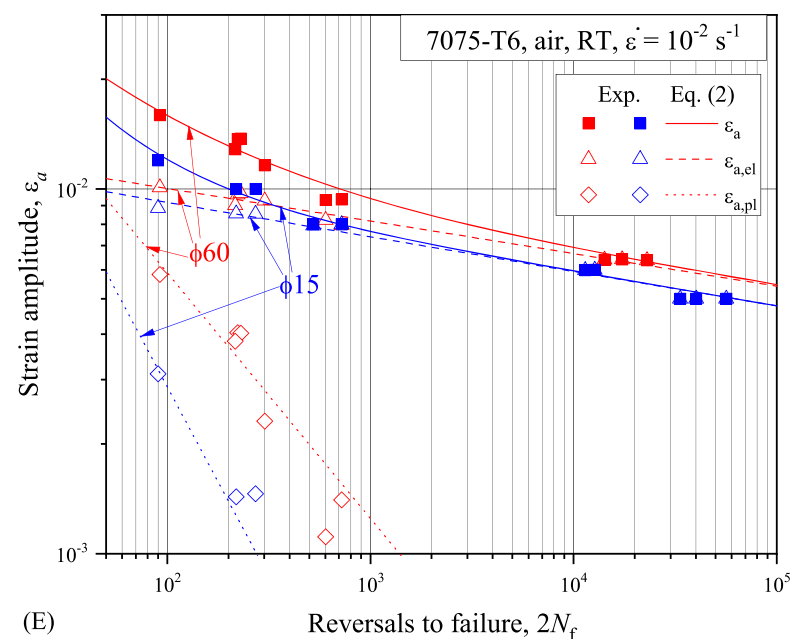

F I G U RE 8 Principal results of the low-cycle fatigue tests. (A, B) Evolution of the stress amplitude versus number of strain cycles. (C, D) Stabilized hysteresis loops at half fatigue life. (A-C) $\$ 15$; (B-D) $\phi 60$. (E) Experimental data versus Basquin and Coffin-Manson equations [Colour figure can be viewed at wileyonlinelibrary.com]

\begin{tabular}{llllllll} 
Variant & $\boldsymbol{E}(\mathbf{M P a})$ & $\sigma_{\boldsymbol{f}}^{\prime}(\mathbf{M P a})$ & $\boldsymbol{b}$ & $\varepsilon_{\boldsymbol{f}}^{\prime}$ & $\boldsymbol{c}$ & $\boldsymbol{H}(\mathbf{M P a})$ & $\boldsymbol{n}$ \\
\hline 60 & 70,500 & 1,067 & -0.0893 & 0.131 & -0.674 & 617 & 0.0233 \\
$\phi 15$ & 70,500 & 1,002 & -0.0948 & 0.349 & -1.04 & 654 & 0.0157
\end{tabular}

T A B L E 4 Basquin, Coffin-Manson (Equations 2a and 2b) of the LCF curve and Ramberg-Osgood parameters (Equation 5) of the cyclic stress-strain curves 


$$
\varepsilon=\frac{\sigma}{E}+\left(\frac{\sigma}{H}\right)^{1 / n}
$$

The best-fit parameters are listed in Table 4. Figure 9A compares the cyclic with the monotonic stress-strain curves of the two material conditions. Interestingly, both conditions display a cyclic hardening behavior, but this latter is much more pronounced in $\phi 60$ as a consequence of the above-mentioned superior plastic resources. As a result, while the monotonic curve of $\phi 15$ is constantly above that of $\phi 60$, exactly the opposite occurs for the cyclic curve. This outcome is of paramount importance when designing parts made of this alloy necessitate mechanical treatments, like shot peening or ball burnishing, which involve intense plastic deformation of the surface layers. Evidently, these are expected to be beneficial only if the starting material has adequate cyclic plastic resources.

\section{4 | High-cycle fatigue properties}

The results of the HCF tests are plotted in Figure 9B. The main results in terms of $5 \times 10^{6}$ fatigue strength and best-fit coefficients of Equation 3 are listed in Table 5.

The scenario depicted in Figure $9 \mathrm{~B}$ and Table 5 is completely different from what illustrated for LCF properties in Figures 8E and 9A. The $\phi 15$ variant outperforms $\phi 60$ in the entire explored HCF regime. Apparently, the superior grain size refinement and finer dispersion of intermetallic precipitates (see Section 3.1) as a result of the higher extrusion ratio experienced by $\phi 15$ are very beneficial to the HCF strength. Since the stress field remains essentially elastic, the loss in cyclic plasticity reported in Section 3.3 is not detrimental to the fatigue strength in this regime. In other words, the different cyclic hardening behavior is here inactivated, and the trend in HCF properties is in line with the monotonic properties. This is particularly true at the very high cycle fatigue regime; indeed, the fatigue strength at $5 \times 10^{6}$ cycles of $\phi 15$ is about $40 \%$ higher than that of $\phi 60$, while this increment drops down to $30 \%$ in the intermediate cycle regime at $5 \times 10^{4}$ cycles.

SEM analyses were carried out on the fracture surfaces of the specimens tested at load levels close to the $5 \times 10^{6}$ cycles fatigue endurance to shed light on the damage mechanism acting in the $\mathrm{HCF}$ regime. As illustrated in Figure 10A,C, for $\phi 60$ and $\phi 15$, respectively, fatigue failure occurred in both variants through the nucleation of one single dominant crack in the immediate vicinity of the outer surface of the specimen. Micrographs of the crack initiation site at higher magnification are reported in Figure 10B,D. It can be noted that the very early crack propagation shows a cleavage-like microstructure caused by transcrystalline sliding fracture. This is frequently observed in $\mathrm{Al}$ alloys when fatigue tests are conducted under vacuum. ${ }^{18-20}$ In the present work, this evidence can be explained by the fact that the first propagation stages of sub-superficial cracks occur at very low partial pressures of oxygen, as already observed in shot peened $\mathrm{Al}$ specimens. ${ }^{21}$ As soon as the crack emerges to the outer surface, the resulting penetration of air changes the fracture mechanism, which becomes intergranular. The fracture surfaces are flat and approximately oriented
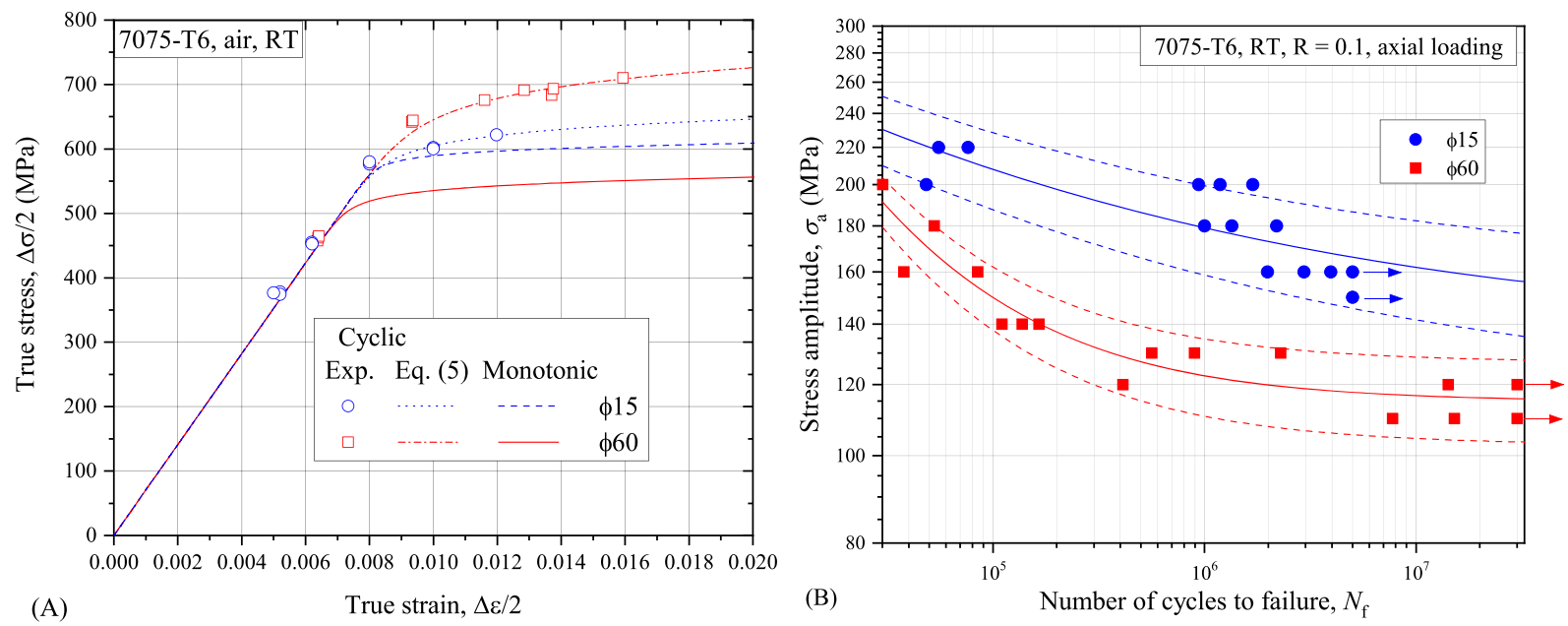

F I G U RE 9 (A) Comparison between monotonic and cyclic stress strain curve. (B) Results of high-cycle fatigue experiments and fit curves. Run-out tests are marked by arrows. Dashed lines correspond to the fatigue strengths for the various specimens at $10 \%$ and $90 \%$ failure probabilities [Colour figure can be viewed at wileyonlinelibrary.com] 


\begin{tabular}{llllcl} 
Variant & $\boldsymbol{k}_{\mathbf{1}}(\mathbf{M P a})$ & $\boldsymbol{k}_{\mathbf{2}}(\mathbf{M P a})$ & $\boldsymbol{m}$ & $\boldsymbol{S}(\mathbf{M P a})$ & $\boldsymbol{S}_{\boldsymbol{e}}$ at $\mathbf{5} \times \mathbf{1 0}^{\mathbf{6}}$ cycles $(\mathbf{M P a})$ \\
$\phi 60$ & 114.8 & 62,347 & 0.651 & 9.43 & 117.6 \\
$\phi 15$ & 136.9 & 969.6 & 0.227 & 15.9 & 166.2 \\
\hline
\end{tabular}

TA B LE 5 Best-fit coefficients of Equation 3 used to interpolate the HCF test results
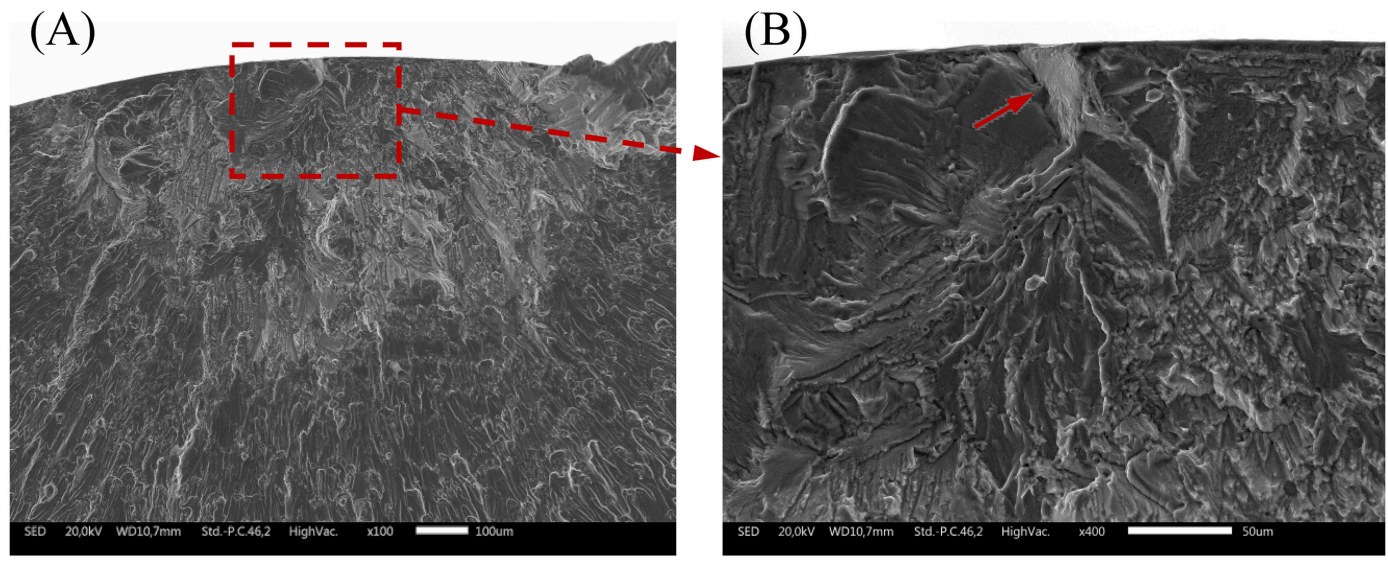

(C)

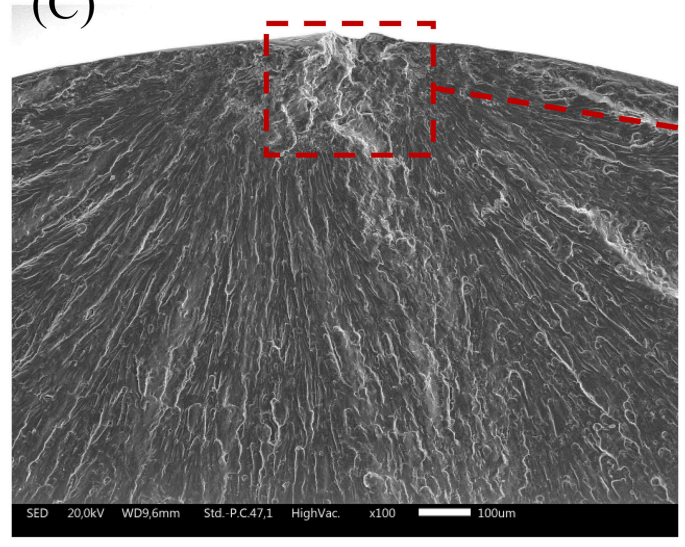

(D)

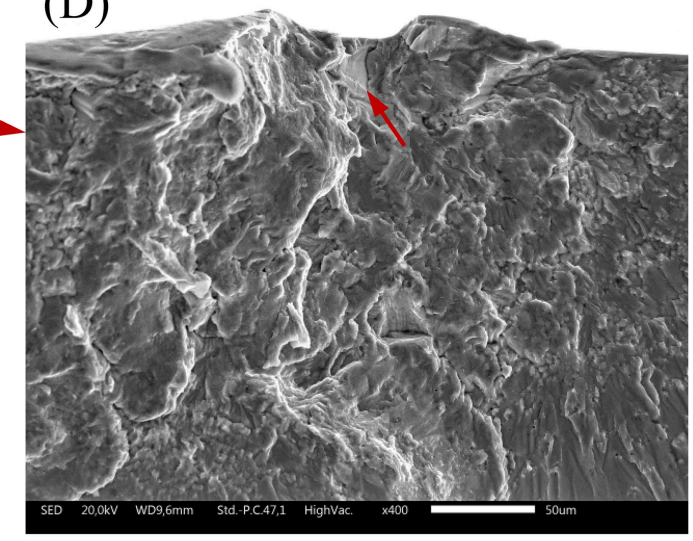

F I G U RE 10 SEM micrographs of the fracture surfaces of samples tested in the high cycle fatigue regime at $R=0.1$. (A, B) $\phi$ $60\left(\sigma_{\mathrm{a}}=110 \mathrm{MPa}, N_{\mathrm{f}}=1.518 \times 10^{7}\right) ;(\mathrm{C}, \mathrm{D}) \phi 15\left(\sigma_{\mathrm{a}}=180 \mathrm{MPa}, N_{\mathrm{f}}=2.138 \times 10^{6}\right)$. The crack initiation site is marked by a red arrow [Colour figure can be viewed at wileyonlinelibrary.com]

orthogonally to the load axis. Looking at Figure 10B, it can be noted that the cleavage-like fracture starts (as indicated by a red arrow) from a particle of about $10 \mu \mathrm{m}$ diameter. This size is in good agreement with that found for the intermetallic precipitates analyzed in Section 3.1 and suggests the idea that these microstructural constituents act as preferential fatigue crack nucleation sites. The magnification of the crack initiation site reported in Figure 10D for $\phi 15$ did not permit to reveal the presence of precipitates, apparently due to their much finer size. Even though we could not indicate the intermetallic inclusion as the microstructural constituent triggering the fatigue crack initiation in $\phi 15$ variant, there is in the scientific literature ${ }^{6,13}$ a vast variety of experimental proofs supporting this hypothesis.
On the base of these observations, the superior HCF strength displayed by $\phi 15$ can be imputed to higher work hardening resulting in higher yield and ultimate tensile strength along with smaller intermetallic precipitates that negatively impact on the fatigue crack initiation resistance. A very powerful model to incorporate material strength and defectiveness characteristics into a fatigue prediction tool was devised by Murakami and Endo ${ }^{22}$ and successfully applied to a wide spectrum of $\mathrm{Fe}^{9}$ and $\mathrm{Ti}^{23,24}$ alloys. It is based on the well-known $\sqrt{\text { area }}$ parameter, defined as the square root of the area obtained by projecting a defect or a crack onto the plane perpendicular to the maximum tensile stress. The material strength characteristic is defined in terms of Vickers hardness. This term however turned out to be scarcely 
T A B LE 6 Comparison between experimental value of fatigue endurance and predictions made by Equation 6 for several Al alloys tested in the technical literature

\begin{tabular}{|c|c|c|c|c|c|c|}
\hline Condition & Source & Stress ratio $R$ & $S_{Y}(\mathrm{MPa})$ & $\sqrt{\text { area }}(\mu \mathrm{m})$ & \multicolumn{2}{|c|}{$S_{e}(\mathrm{MPa})$} \\
\hline 7075-Т6 ф60 & present study & 0.1 & 531 & 13.5 & 117.6 & 120.5 \\
\hline 7075-Т6 ф15 & present study & 0.1 & 592 & 4.8 & 166.2 & 159.6 \\
\hline 7075-Т651 & 21,27 & 0.05 & 515 & 9.3 & 124.2 & 125.3 \\
\hline
\end{tabular}

representative of the fatigue strength of $\mathrm{Al}$ alloys, and therefore, Murakami model is rarely used to this kind of metallic materials. In addition, the slightly difference in Vickers hardness reported in Table 2 points out that this material property is not able to justify the large difference found in terms of HCF strength for the two material variants. Deguchi et al., ${ }^{25}$ and, more recently, Borsato et al. ${ }^{26}$ proposed to modify Murakami's model for cast irons by replacing the Vickers hardness with the yield and/or the ultimate tensile strength. Looking at Table 3, it can be noted that actually these two monotonic strength characteristics better reflect the difference in HCF strength, especially the yield stress. For this reason, we propose here to interpret the HCF behavior of the investigated material conditions through the following expression based on a modified version of Murakami's model for predicting the high cycle fatigue endurance $S_{e}$ :

$$
S_{e}=C \cdot \frac{S_{Y}}{(\sqrt{\text { area }})^{1 / 6}},
$$

where $C$ is a constant incorporating the effect stress ratio $R$ and location of the crack initiation site. Since these are the same for the two investigated conditions (viz., $R=0.1$ and near surface crack initiation site), we can assume that $C$ takes the same value for $\phi 15$ and $\phi 60$ variants. Importantly, the ratio between the fatigue endurance $S_{e}$ of $\phi 60$ to $\phi 15$ is 0.71 , in very good agreement with the ratio estimated by Equation 6 equal to 0.75, when the $\sqrt{\text { area }}$ parameter is calculated considering the maximum intermetallic precipitate size found during the metallographic analyses reported in Section 3.1 $\left(\right.$ area $=\frac{\pi}{4} D_{\text {circle, } \max }^{2}$ ). The two experimental $S_{e}$ values can be then used to get a best-fit estimation of the constant $C$, which was assessed equal to 0.35 .

To check the reasonability of the proposed fatigue calculation method, we compare the experimental value with the prediction of Equation 6 for two independent fatigue scenarios not used to calibrate the constant $C$. The former is a rolled aeronautical Al grade 7075-T651, which was fatigue tested by Benedetti et al. ${ }^{21,27}$ In this case as well, a fine dispersion of intermetallic precipitates of maximum size of about $10 \mu \mathrm{m}$ emerged from metallographic analyses. The latter is a cast $\mathrm{Al}$ grade $\mathrm{AlSi} 10 \mathrm{Mg}$ additively manufactured by Avanzini et al. ${ }^{28}$ via laser powder bed fusion. Fractographic inspections on fatigued specimens revealed that near-surface pores of about $90 \mu \mathrm{m}$ equivalent diameter were the main source of fatigue crack initiation. Table 6 compares the experimental values of the high cycle fatigue endurance of the above-mentioned $\mathrm{Al}$ variants with the predictions made by Equation 6, keeping the same value of the constant $C$ found before (0.35). A very good agreement is obtained, being the relative absolute error below a few percent. Clearly, a more extended validation campaign is necessary to extend the applicability of the prediction model to different crack initiation locations and load ratios. It can be argued that $\sqrt{\text { area }}$ parameter controls the contribution of impurities to the HCF strength decrement and $S_{Y}$ is a measure of how the material withstands plastic slip of crystalline planes, a crucial aspect in dictating the fatigue properties.

In conclusion, it can be observed that a large variability in static and fatigue properties is present in formally identical supplies of aeronautical $\mathrm{Al}$ grade 7075-T6, even though the chemical composition and the aging treatment are compliant with the standard specifications. Indeed, different extrusion ratios to achieve different bar diameters and small variation in chemical compositions (especially in impurities like $\mathrm{Si}$ and $\mathrm{Fe}$ ) lead to a noticeable variability in static and cyclic properties. Such fluctuations cannot be adequately captured by simple hardness or microhardness measurements usually done in alloy certification tests. Conversely, to get a satisfactorily accurate knowledge of the HCF fatigue properties, it is recommended to carry out on coupons, extracted from the raw material supply, monotonic tensile tests, and metallographic analyses. The knowledge of yield stress and maximum size of intermetallic precipitates allows a fairly accurate prediction of the fatigue endurance by means of Equation 6. 


\section{4 | CONCLUSIONS}

The present paper investigated the variability in microstructure, monotonic, and cyclic properties of two nominally identical supplies of aeronautical Al grade 7075-T6. The following conclusions can be drawn:

1. The presence of a high content of impurities like Fe and $\mathrm{Si}$ promotes the precipitation of intermetallic particles, which impact negatively on the mechanical properties. A higher extrusion ratio to achieve a smaller bar diameter leads to a finer grain size with a finer dispersion of intermetallic precipitates.

2. Such refinement, especially in intermetallic particles, is beneficial for yield stress, ultimate tensile strength, total elongation, and especially for the high-cycle fatigue strength. The observed noticeable increment in such mechanical properties is not reflected by a comparable increment in hardness or microhardness.

3. The work hardening produced by the higher extrusion ratio remarkably reduces the cyclic hardening capability of the material and therefore impacts negatively on its low-cycle fatigue properties. This effect must be taken into consideration when the alloy is subject to intense plastic deformation prior to service.

4. The high-cycle fatigue strength is directly related to the yield stress and the size of the maximum intermetallic precipitate. A simple model based on Murakami $\sqrt{\text { area }}$ parameter can be used to predict the HCF endurance. Therefore, it is recommended to carry out monotonic tensile tests and microstructural analysis for a proper certification of the mechanical properties of the material supply.

\section{DATA AVAILABILITY STATEMENT}

Data are available on request from the authors.

\section{ORCID}

\section{Matteo Benedetti (D) https://orcid.org/0000-0001-9158-2429}

\section{REFERENCES}

1. ASM Handbook. Properties and Selection: Nonferrous Alloys and Special-Purpose Materials. Vol. 2. ASM International; 1990.

2. Dursun T, Soutis C. Recent developments in advanced aircraft aluminium alloys. Mater des. 2014;56:862-871.

3. Melhem GN. Aerospace fasteners: use in structural applications. In: Encyclopedia of Aluminum and Its Alloys. Boca Raton: CRC Press; 2019.

4. Zou X, Yan H, Chen X. Evolution of second phases and mechanical properties of $7075 \mathrm{Al}$ alloy processed by solution heat treatment. Trans Nonferrous Met Soc Chin. 2017;27(10): 2146-2155.

5. Starke EA, Staley JT. Application of modern aluminum alloys to aircraft. Prog Aerosp Sci. 1996;32(2-3):131-172.
6. Payne J, Welsh G, Christ RJ Jr, Nardiello J, Papazian JM. Observations of fatigue crack initiation in 7075-T651. Int $J$ Fatigue. 2010;32(2):247-255.

7. Yang Y, Zhang Z, Li X, Wang Q, Zhang Y. The effects of grain size on the hot deformation and processing map for 7075 aluminum alloy. Mater des. 2013;51:592-597.

8. Koizumi T, Kuroda M. Grain size effects in aluminum processed by severe plastic deformation. Mater Sci Eng A. 2018; 710:300-308.

9. Benedetti M, Fontanari V, Barozzi M, Gabellone D, Tedesco MM, Plano S. Low and high-cycle fatigue properties of an ultrahigh-strength TRIP bainitic steel. Fatigue Fract Eng Mater Struct. 2017;40(9):1459-1471.

10. Huang K, Logé RE. A review of dynamic recrystallization phenomena in metallic materials. Maternite. 2016;111:548-574.

11. Sheppard T. Extrusion of Aluminium Alloys. Springer US: Boston, MA; 1999.

12. Rokni MR, Zarei-Hanzaki A, Abedi HR. Microstructure evolution and mechanical properties of back extruded 7075 aluminum alloy at elevated temperatures. Mater Sci Eng A. 2012;532: 593-600.

13. Ghosh A, Ghosh M, Shankar G. On the role of precipitates in controlling microstructure and mechanical properties of $\mathrm{Ag}$ and Sn added 7075 alloys during artificial ageing. Mater Sci Eng A. 2018;738:399-411.

14. Singh SS, Schwartzstein C, Williams JJ, Xiao X, De Carlo F, Chawla N. 3D microstructural characterization and mechanical properties of constituent particles in $\mathrm{Al} 7075$ alloys using X-ray synchrotron tomography and nanoindentation. J Alloys Compd. 2014;602:163-174.

15. Gao M, Feng CR, Wei RP. An analytical electron microscopy study of constituent particles in commercial 7075-T6 and 2024-T3 alloys. Metall Mater Trans a. 1998;29(4):1145-1151.

16. Isadare $\mathrm{AD}$, Aremo $\mathrm{B}$, Adeoye MO, Olawale OJ, Shittu MD. Effect of heat treatment on some mechanical properties of 7075 aluminium alloy. Mater Res. 2012;16(1):190-194.

17. Benedetti M, Fontanari V, Monelli BD. Numerical simulation of residual stress relaxation in shot peened high-strength aluminum alloys under reverse bending fatigue. J Eng Mater Technol. 2010;132:011012. https://doi.org/10.1115/1.3184083

18. Wang Q, Kawagoishi N, Chen Q. Fatigue and fracture behaviour of structural Al-alloys up to very long life regimes. Int $J$ Fatigue. 2006;28(11):1572-1576.

19. Pyttel B, Schwerdt D, Berger C. Very high cycle fatigue-is there a fatigue limit? Int J Fatigue. 2011;33(1):49-58.

20. Bonakdar A, Wang F, Williams JJ, Chawla N. Environmental effects on fatigue crack growth in 7075 aluminum alloy. Metall Mater Trans a. 2012;43(8):2799-2809.

21. Benedetti M, Fontanari V, Bandini M, Savio E. High- and very high-cycle plain fatigue resistance of shot peened high-strength aluminum alloys: the role of surface morphology. Int J Fatigue. 2015;70:451-462.

22. Murakami Y, Endo M. Effects of hardness and crack geometries on $k$ th of small cracks emanating from small defects. In: Miller KJ, de los Rios ER, eds. The Behaviour of Short Fatigue Cracks. London: Mechanical Engineering Publications; 1986: 275-293.

23. Benedetti M, Fontanari V, Bandini M, Zanini F, Carmignato S. Low- and high-cycle fatigue resistance of Ti-6Al-4V ELI 
additively manufactured via selective laser melting: Mean stress and defect sensitivity. Int J Fatigue. 2018;107:96-109.

24. Benedetti M, Santus C. Notch fatigue and crack growth resistance of Ti-6Al-4V ELI additively manufactured via selective laser melting: a critical distance approach to defect sensitivity. Int J Fatigue. 2019;121:281-292.

25. Deguchi $\mathrm{T}$, Matsuo $\mathrm{T}$, Kim $\mathrm{H}$, Ikeda $\mathrm{T}$, Endo M. Fatigue strength evaluation of ferritic-pearlitic ductile cast iron with notches and holes of various sizes. Adv Exp Mech. 2017;2:87-91.

26. Borsato T, Ferro P, Berto F. Novel method for the fatigue strength assessment of heavy sections made by ductile cast iron in presence of solidification defects. Fatigue Fract Eng Mater Struct. 2018;41(8):1746-1757.

27. Benedetti M, Fontanari V, Scardi P, Ricardo CLA, Bandini M. Reverse bending fatigue of shot peened 7075-T651 aluminium alloy: the role of residual stress relaxation. Int J Fatigue. 2009; 31(8-9):1225-1236.

28. Avanzini A, Battini D, Gelfi M, et al. Investigation on fatigue strength of sand-blasted DMLS-AlSi10Mg alloy. Procedia Struct Integr. 2019;18:119-128.

How to cite this article: Benedetti $M$, Menapace C, Fontanari V, Santus C. On the variability in static and cyclic mechanical properties of extruded 7075-T6 aluminum alloy. Fatigue Fract Eng Mater Struct. 2021;44(11): 2975-2989. https://doi.org/10.1111/ffe.13530 